\title{
Clinical value of O-(2-[18 F]-fluoroethyl)-L-tyrosine positron emission tomography in patients with low-grade glioma
}

\author{
Marion Rapp, M.D., ${ }^{1}$ Frank W. Floeth, M.D. $, 1,3$ Jörg Felsberg, M.D., ${ }^{2}$ \\ Hans-Jakob Steiger, M.D., ${ }^{1}$ Michael Sabel, M.D., ${ }^{1}$ Karl-Josef Langen, M.D. ${ }^{4}$ \\ AND NorberT GaLldiKs, M.D.,
}

Departments of ${ }^{1}$ Neurosurgery and ${ }^{2}$ Neuropathology, University of Duesseldorf; ${ }^{3}$ Department of Spine and Pain, St.-Vinzenz-Hospital, Duesseldorf; ${ }^{4}$ Institute of Neuroscience and Medicine, Research Center Jülich; and ${ }^{5}$ Department of Neurology, University of Cologne, Germany

\begin{abstract}
Progress in morphological imaging has facilitated the diagnosis of low-grade glioma (LGG) and plays a decisive role in therapeutic decisions. To date, the method of choice is contrast-enhanced MRI including T1-/T2-weighted and FLAIR sequences. However, tumor delineation and the differentiation between neoplastic and normal brain tissue can be difficult when using morphological MRI and may complicate the identification of anaplastic foci for biopsy and further treatment planning. Furthermore, therapy monitoring and the differentiation of tumor recurrence from unspecific post-therapeutic changes in the tissue are challenging. Additional information about tumor metabolism may be very helpful for the diagnostic assessment of LGG and can be provided by PET. In recent years, the PET amino acid tracer O- $\left(2-\left[{ }^{18} \mathrm{~F}\right]\right.$-fluoroethyl)-L-tyrosine $\left({ }^{18} \mathrm{~F}-\mathrm{FET}\right)$ has been clinically validated for brain tumor diagnosis. This tracer has logistical advantages over the widely used PET tracer ${ }^{11} \mathrm{C}$-methyl-L-methionine due to the longer half-life of the ${ }^{18} \mathrm{~F}$-label (109 vs 20 minutes, respectively). Additionally, it has been demonstrated that both tracers provide comparable diagnostic information. The authors provide an overview of the recent literature regarding the value of various clinical applications of ${ }^{18} \mathrm{~F}-\mathrm{FET}$ PET in patients with LGG.

(http://thejns.org/doi/abs/10.3171/2012.12.FOCUS12336)
\end{abstract}

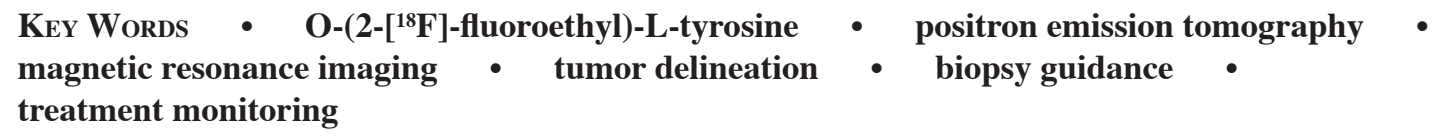

$\mathrm{T}$ lhe term "low-grade glioma" includes all WHO Grade I and II gliomas. According to the WHO classification, ${ }^{36}$ the most important WHO Grade II histological subtypes are astrocytomas, oligodendrogliomas, and oligoastrocytomas. The incidence of LGG in Europe is approximately $1.5 / 100,000$ patients/year (astrocytic LGG, 1.2/100,000 patients/year; oligodendroglial LGG, 0.3/100,000 patients/year), ${ }^{6}$ accounting for nearly $15 \%$ of all primary brain tumors. At the time of diagnosis, patients with LGG are typically affected at an average age of 40 years. ${ }^{48}$ Regarding the anatomical localization, there is a predilection for eloquent areas such

\footnotetext{
Abbreviations used in this paper: EORTC $=$ European Organisation for Research and Treatment of Cancer; $\mathrm{HGG}=$ high-grade glioma; LGG = low-grade glioma; MRS = MR spectroscopy; NCCTG = North Central Cancer Treatment Group; NPV = negative predictive value; $\mathrm{PPV}=$ positive predictive value; 5 -ALA = 5-aminolaevulinic acid; ${ }^{11} \mathrm{C}-\mathrm{MET}={ }^{11} \mathrm{C}$-methyl-L-methionine; ${ }^{18} \mathrm{~F}-\mathrm{FET}=\mathrm{O}-\left(2-\left[{ }^{18} \mathrm{~F}\right]-\right.$ fluoroethyl)-L-tyrosine.
}

as the insula or the supplementary motor area. ${ }^{7}$ In up to $80 \%-90 \%$ of all patients with LGG, the most common initial clinical presentation is partial or generalized epileptic seizures. ${ }^{57}$ Epileptic seizures are more frequently associated with cortically based tumors, particularly in frontal, temporal, and insular locations and with oligodendroglial tumors. Depending on histological subtype, the 5-year survival rate is approximately $40 \%-50 \%$ in astrocytoma patients and $65 \%-80 \%$ in oligodendroglioma patients. ${ }^{6,28}$ The 3 largest randomized trials (EORTC 22844, EORTC 22845, and the NCCTG trial) together studied more than 800 patients with LGG, and 58\%-72\% of patients were alive at 5 years from the time of diagnosis. ${ }^{17}$ Furthermore, it could be demonstrated that several factors may affect survival negatively: age greater than 40 years, astrocytoma histology, maximum tumor diameter $\geq 6 \mathrm{~cm}$, tumor crossing the corpus callosum, and the presence of a neurological deficit (except epileptic seizures) before surgery. ${ }^{42}$

Treatment remains challenging, and to date there is 
no randomized prospective study defining the impact of gross-total surgery, chemotherapy, or radiotherapy. 3,48,56,57

Today, a general consensus for treatment is radical tumor resection if possible and subsequent chemotherapy, especially in high-risk patients with incomplete resection. The chemosensitivity of oligodendroglial tumors is higher than that of astrocytic tumors and is associated with the loss of heterozygosity on chromosome 1p/19q. ${ }^{50}$ Furthermore, postoperative radiotherapy may be considered as it leads to longer symptom-free survival, with no influence on overall survival but with reduced quality of life. ${ }^{4,29,54,64}$

To date, morphological MRI is the most important diagnostic tool for assessing LGG. Signal alterations of LGG are usually characterized by homogeneous iso- to hypointense signal changes on T1-weighted images and hyperintense signal changes on T2-weighted or FLAIR images (Fig. 1). Furthermore, oligodendrogliomas in particular exhibit calcifications in $20 \%$ of all cases, ${ }^{23}$ which can be observed best on CT scans. Contrast enhancement is infrequently seen, in approximately $30 \%$ of LGG patients $^{16}$ (Fig. 2). The risk of anaplasia in nonenhancing lesions increases with patient age. ${ }^{2}$

Basing the diagnosis of an LGG on the aforemen-
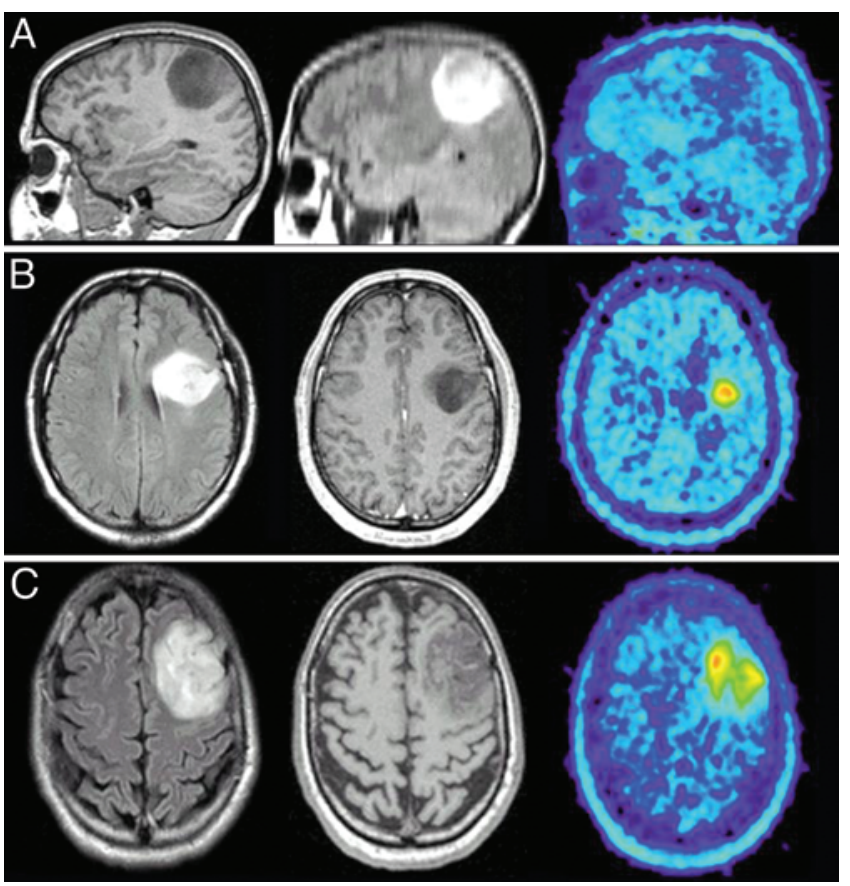

FIG. 1. A: Studies obtained in a 29-year-old woman with a right parietal astrocytoma (WHO Grade II). The sagittal MR images reveal a large, circumscribed, and nonenhancing lesion with ${ }^{18} \mathrm{~F}-\mathrm{FET}$ uptake below the cortical level in the corresponding PET scan indicating a favorable prognosis. B: Studies obtained in a 54-year-old man with a left insular oligoastrocytoma (WHO Grade II). The transaxial MR images demonstrate a hyperintense, circumscribed lesion without contrast enhancement. In contrast to the lesion size on MRI, the corresponding PET scan shows a smaller, circumscribed lesion with increased ${ }^{18} \mathrm{~F}$ FET uptake, facilitating biopsy guidance. C: Studies obtained in a 44-year-old woman with a left frontal oligodendroglioma (WHO Grade II). The transaxial MR images demonstrate a diffuse and nonenhancing lesion, with inhomogeneous and increased ${ }^{18} \mathrm{~F}$-FET uptake on the PET scan, which helps to guide biopsy.
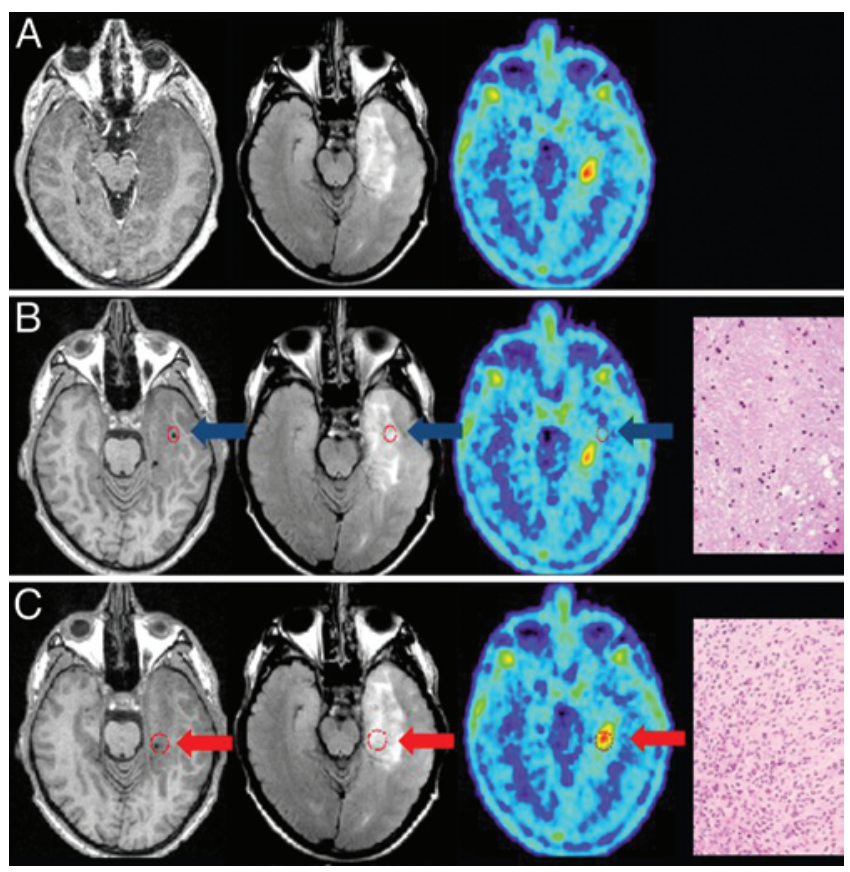

Fig. 2. Studies obtained in a 34-year-old man with a left temporal lesion. A: The MR images show a large, diffuse, nonenhancing lesion suspicious for a diffuse LGG. Differentiation of tumor extent, edema, and peritumoral brain tissue is not possible, and information derived from the MR images does not provide a favorable biopsy target. The corresponding PET scan demonstrates a small area of focally increased ${ }^{18} \mathrm{~F}$-FET uptake at the medial aspect of the temporal lobe within the large area of hyperintense signal alterations on MRI. B: Serial stereotactic biopsies were performed and titanium markers (black points within red circles on the T1-weighted images) are left for exact documentation of the biopsy sites. The first biopsy was performed within the area of abnormal signal on MRI and normal ${ }^{18} \mathrm{~F}-\mathrm{FET}$ accumulation on the PET scan (blue arrows). The photomicrograph reveals peritumoral tissue with edema and reactive astrogliosis without tumor cells. C: The second biopsy was performed within the area of abnormal signal on MR images and high accumulation of ${ }^{18} \mathrm{~F}-\mathrm{FET}$ on the PET scan (red arrows). The photomicrograph shows tumor tissue with all the features of an anaplastic astrocytoma (WHO Grade III). $\mathrm{H} \& \mathrm{E}$, original magnification $\times 400$ (B and C).

tioned MRI findings alone is, however, a common source of error. Kondziolka and colleagues ${ }^{30}$ reported a falsepositive rate of $50 \%$ for the prediction of glioma histology based on the typical MRI appearance. Additionally, low sensitivity (range 72\%-93\%) and specificity (range $50 \%-80 \%$ ) values have been reported for standard morphological MRI protocols of suspected LGG. ${ }^{31}$ Thus, the results of these studies indicate that morphological MRI alone cannot be used as a reliable tool to predict the histological diagnosis in patients with LGG. Consequently, alternative diagnostic methods are needed to improve the diagnostic accuracy. Metabolic imaging using PET with radiolabeled amino acids might help to overcome some of these limitations.

\section{O-(2-18F-fluoroethyl)-L-tyrosine PET}

The most widely used tracer for amino acid PET is ${ }^{11} \mathrm{C}$-MET, but because of its short physical half-life (20 minutes), the use of ${ }^{11} \mathrm{C}-\mathrm{MET}$ remains restricted to a few 
PET centers possessing a cyclotron unit onsite and could not be established in routine clinical practice despite convincing clinical results. In contrast, ${ }^{18} \mathrm{~F}-\mathrm{FET}$ is one of the first ${ }^{18} \mathrm{~F}$-labeled amino acids that can be produced in large amounts for clinical purposes and is applicable in PET studies using a satellite concept similar to that of the widely used PET tracer ${ }^{18} \mathrm{~F}-\mathrm{FDG}\left({ }^{18} \mathrm{~F}\right.$-2-fluoro-2-deoxyD-glucose). ${ }^{19,69}$

Although ${ }^{18} \mathrm{~F}$-FET is not incorporated into proteins (in contrast to ${ }^{11} \mathrm{C}-\mathrm{MET}$ ), uptake by tumor cells is stereospecific and mediated by amino acid transporters. ${ }^{22,34}$ Initial studies using ${ }^{18} \mathrm{~F}$-FET PET for the analysis of human brain tumors and rat gliomas have shown results similar to those obtained with ${ }^{11} \mathrm{C}$-MET PET. ${ }^{18,34,66}$

Comparative studies of ${ }^{18} \mathrm{~F}$-FET and ${ }^{11} \mathrm{C}$-MET have shown that tumor-to-brain contrast of ${ }^{18} \mathrm{~F}$-FET appears to be very similar to that of ${ }^{11} \mathrm{C}-\mathrm{MET},{ }^{66}$ so that clinical experiences gained with both tracers can be considered together. In contrast to ${ }^{11} \mathrm{C}-\mathrm{MET}$, animal experiments have shown that ${ }^{18} \mathrm{~F}$-FET exhibits no uptake in inflammatory cells and in inflammatory lymph nodes, promising a higher specificity for the detection of tumor cells. ${ }^{33}$ Nevertheless, false-positive uptake has been observed for both tracers in brain abscesses, demyelinating processes, cerebral ischemia, and hematomas. Therefore, increased uptake of the tracers is not specific for cerebral gliomas, although high amino acid uptake has a high PPV for cerebral gliomas. For both tracers, a patient's radiation exposure remains within the same order of magnitude as that of conventional radiological studies ${ }^{35}$ No side effects have been reported to date with the use of these tracers after several thousand studies have been performed worldwide. The duration of tracer uptake and image acquisition with any of these radiopharmaceuticals is about 30-50 minutes. The costs of ${ }^{18} \mathrm{~F}$-FET PET are comparable to those of ${ }^{18} \mathrm{~F}$-FDG PET. An ${ }^{11} \mathrm{C}$-MET PET study is more expensive because only very few patients can be examined with one synthesis due to the short half-life of ${ }^{11} \mathrm{C}$.

\section{Clinical Applications of ${ }^{18}$ F-FET PET}

\section{Preoperative Detection of LGG and Differentiation From $H G G$}

In morphological MRI, nonenhancing space-occupying lesions are often suspicious for LGG (Figs. 1 and 2). However, these lesions constitute a heterogeneous group of diseases, including HGGs and nonneoplastic lesions, such as cerebral hematoma, ischemia, and inflammatory processes. Incorrect interpretation of morphological MRI features may result in necessary treatment being deferred or otherwise unnecessarily exaggerated. Regarding the diagnostic accuracy of morphological MRI, it was demonstrated in a biopsy-controlled study that morphological MRI had a high sensitivity of $96 \%$ for the detection of tumor tissue but a specificity of only 53\%. ${ }^{39}$ Similar results for morphological MRI alone were observed in a study with a larger number of patients $(n=176) .{ }^{37}$ In comparison with morphological MRI, the sensitivity of ${ }^{18} \mathrm{~F}$-FET PET to detect LGG is lower because increased ${ }^{18} \mathrm{~F}$-FET exhibits increased uptake is present in only $60 \%-80 \%$ of the patients..$^{10,27,40,41}$ However, the results of previous studies suggest a clearly higher specificity of ${ }^{18} \mathrm{~F}-\mathrm{FET}$ PET for detecting high-grade tumors and differentiating them from LGG than morphological MRI.

In a large patient series, 88 patients underwent ${ }^{18} \mathrm{~F}$ FET PET for evaluation of an untreated and undiagnosed intracerebral mass or lesion detected on MRI. ${ }^{41}$ In 60 patients the diagnosis was confirmed histologically, and 19 of the 60 patients had an LGG. In the remaining 28 patients, the diagnosis was confirmed by clinical follow-up. Despite the large number of patients without histological confirmation of the diagnosis $(n=28)$, the sensitivity of ${ }^{18} \mathrm{~F}-\mathrm{FET}$ PET for detecting a high-grade tumor entity was $93 \%$, with a low specificity of $56 \%$ due to the number of LGGs. The PPV was $67 \%$ and the NPV was $89 \%$.

In a recent study with a larger patient population, the diagnostic performance of ${ }^{18} \mathrm{~F}$-FET PET was evaluated in a series of 174 newly diagnosed cerebral lesions suspected to be primary brain tumors, which included 77 histologically confirmed LGGs. ${ }^{49}$ Furthermore, 72 high-grade tumors and 25 nonneoplastic lesions were diagnosed histologically. In that study, the diagnostic value of simple maximum tumor-to-background ratios for differentiation between high-grade tumors and LGGs was evaluated using receiver-operating-characteristic curve analyses. At a threshold of 2.5 , the sensitivity was $80 \%$ and the specificity was $65 \%$. The PPV was $66 \%$ and the NPV was $79 \%$.

Furthermore, Jansen and colleagues ${ }^{27}$ investigated the discriminative value of the additional ${ }^{18} \mathrm{~F}-\mathrm{FET}$ PET imaging parameter in patients with newly diagnosed cerebral lesions suspicious for LGG. The authors evaluated ${ }^{18}$ F-FET PET kinetics. HGGs were characterized by an early peak of the time-activity curve at 10-15 minutes after tracer injection, followed by a decrease of ${ }^{18} \mathrm{~F}$-FET uptake. In contrast, slightly and steadily increasing timeactivity curves were frequently found in LGGs. ${ }^{67}$ In the retrospective study by Jansen and colleagues, the authors evaluated the diagnostic value of kinetic ${ }^{18} \mathrm{~F}$-FET PET in 127 patients with newly diagnosed MRI-suspected LGGs prior to histopathological assessment. ${ }^{27}$ They found in the patients with MRI-suspected LGGs that kinetic analysis of ${ }^{18} \mathrm{~F}$-FET uptake enabled the detection HGGs with high accuracy (sensitivity 95\%, specificity $72 \%$, PPV 74\%, and NPV 95\%).

It should be noted, that the specificity of ${ }^{18} \mathrm{~F}-\mathrm{FET}$ PET for neoplastic lesions may be affected by possible tracer uptake in the area of benign processes (for example, cerebral hematoma, ischemia, and inflammatory processes). ${ }^{9,41,51-53}$

In summary, compared with morphological MRI, ${ }^{18}$ F-FET PET adds valuable information to the data acquired in cases of newly diagnosed cerebral lesions suspicious for LGGs. However, a histological biopsy-based evaluation of suspicious brain lesions remains necessary in most circumstances.

\section{${ }^{18}$ F-FET PET-Guided Stereotactic Biopsy and Planning of Resection}

A stereotactic biopsy is often performed for diagnostic purposes before treating patients whose imaging studies highly suggest LGG, especially when an open neurosurgi- 
cal resection for medical reasons, such as eloquent regions and diffuse lesions invading multiple brain lobules, is not possible. However, regarding stereotactic needle biopsy, there is a certain risk of inaccuracy. It could be demonstrated that WHO Grade I gliomas have been "overgraded" in up to $11 \%$ and WHO Grade III gliomas "undergraded" in $28 \%$ of all cases. ${ }^{38}$ Therefore, methods to improve stereotactic biopsy are essential. Since the tumor biology is defined by the most aggressive part of the glioma, representative tissue samples are vitally important for histological tumor diagnosis (Fig. 2). Biopsy-controlled studies have shown that ${ }^{18} \mathrm{~F}$-FET uptake correlates with microvessel and cell density, which is linked to malignant transformation in noncontrast-enhancing gliomas. ${ }^{61,62}$ Biopsy guidance is based on quantitative radioactivity concentration on brain scans as displayed by color-coded radioactivity maps of standardized uptake values (that is, radioactivity concentration divided by the radioactivity injected per gram of body weight). These quantitative scans are coregistered with the corresponding MR images, and biopsies are targeted to the maximum radioactivity concentration in the tumor area. For example, ${ }^{18} \mathrm{~F}-\mathrm{FET}$ PET has been shown to significantly improve the diagnostic efficacy of targeted biopsies, with an accuracy of tumor detection by biopsy of $68 \%$ when using MRI alone, which increased to $88 \%$ when ${ }^{18} \mathrm{~F}$-FET PET information was incorporated. ${ }^{11}$ In a subsequent study, similar results were observed. ${ }^{39}$

Analysis of ${ }^{18} \mathrm{~F}$-FET PET kinetics may also be helpful in the distinction between HGG and LGG tissue and therefore for treatment planning. A recent biopsy-controlled study reported that a homogeneous pattern of uptake kinetics within the tumor is linked to homogeneous histopathological findings, whereas a heterogeneous pattern of uptake kinetics in different parts of the tumor was associated with histopathological heterogeneity. In that study, hot spots exhibiting malignant glioma characteristics covered $4 \%-44 \%$ of the entire tumor volumes. ${ }^{31}$

When tumor resection is planned, the delineation of tumor extent is crucial. A study in patients with LGGs demonstrated an improvement of overall survival after aggressive resection compared with partial resection. ${ }^{56}$ Patients with at least $90 \%$ of their tumors resected had 5 - and 8-year overall survival rates of $97 \%$ and $91 \%$, respectively, whereas patients with less than $90 \%$ of their tumors resected had 5- and 8-year overall survival rates of $76 \%$ and $60 \%$, respectively. Thus, predicted overall survival was negatively influenced even by residual tumor volume of more than $10 \mathrm{ml} .^{56}$

In patients with $\mathrm{HGG}$, fluorescence-guided surgery using 5-ALA is an established intraoperative tool to differentiate between tumor infiltration and normal brain tissue, and thus it facilitates achieving a complete tumor resection. ${ }^{63}$ A biopsy-controlled study in patients with LGG suggested that ${ }^{18} \mathrm{~F}$-FET PET is more sensitive to detect glioma tissue than 5-ALA fluorescence. ${ }^{12}$ The authors found clear differences between ${ }^{18} \mathrm{~F}$-FET uptake and 5-ALA fluorescence owing to the limited sensitivity of 5-ALA to detecting tumor tissue, especially in LGG. They concluded that ${ }^{18} \mathrm{~F}$-FET PET should be considered as an additional tool in resection planning. ${ }^{12}$ These results were confirmed by a subsequent study. ${ }^{8}$
Using PET for resection planning, recent studies demonstrated that ${ }^{11} \mathrm{C}$-MET PET imaging provided a final target contour different from that obtained with MRI alone in about $80 \%$ of the procedures..$^{45}$ Moreover, it was demonstrated in a subsequent study in patients with HGG that complete resection of the increased ${ }^{11} \mathrm{C}$-MET uptake prolongs the survival of these patients. ${ }^{46}$ Because ${ }^{11} \mathrm{C}$ MET and ${ }^{18} \mathrm{~F}$-FET PET provide comparable diagnostic information on gliomas, ${ }^{18}$ these data suggest that resection guided by ${ }^{18} \mathrm{~F}-\mathrm{FET}$ PET may increase the amount of cytoreduction and therefore progression-free and/or overall survival. Prospective studies of LGG patients are needed to confirm these observations.

\section{Use of ${ }^{18} \mathrm{~F}$-FET PET for Assessment of Prognosis}

In patients with LGG, treatment decisions can be challenging and may be influenced by several prognostic factors. Unfavorable prognostic factors are age exceeding 40 years, astrocytoma histology, maximum tumor diameter $\geq 6 \mathrm{~cm}$, tumor crossing the corpus callosum, and the presence of a neurological deficit (except epileptic seizures) before surgery. ${ }^{42}$ Furthermore, a prospective RTOG trial identified a preoperative tumor diameter $>4$ $\mathrm{cm}$, astrocytoma/oligoastrocytoma histology type, and a residual tumor $>1 \mathrm{~cm}$ as predictive of significantly higher recurrence rates. ${ }^{55}$ These factors help to identify patients at low or high risk for rapid tumor progression and to determine when a watchful-waiting approach is justifiable or when LGG patients should be treated early by surgery, radiotherapy, or chemotherapy.

A prospective study in patients with LGG without contrast enhancement on MRI indicated that ${ }^{18} \mathrm{~F}$-FET PET in combination with MRI provides important prognostic information. ${ }^{10}$ Patients with LGG that exhibited increased ${ }^{18} \mathrm{~F}-\mathrm{FET}$ uptake on PET and diffuse tumors on MRI (T2weighted/FLAIR images) had a worse prognosis with shorter life expectancy, rapid tumor progression, and malignant progression to high-grade tumors within only 2-3 years. In contrast, patients with LGG that showed normal or low ${ }^{18} \mathrm{~F}$-FET uptake and circumscribed tumors on MRI (Fig. 1) had a good prognosis with lower risk for tumor progression and lack of malignant transformation within the first 5 years after diagnosis. ${ }^{10}$

Another study analyzed the prognostic impact of ${ }^{18} \mathrm{~F}$ FET PET on small, incidentally detected cerebral lesions on MRI that were suspected of being cerebral glioma. ${ }^{13}$ The authors demonstrated that patients with circumscribed ${ }^{18}$ F-FET PET-negative lesions had an excellent prognosis. At follow-up imaging, most of these lesions vanished (Fig. 3) or remained unchanged (Fig. 4). In the further course of disease, only a minority of patients developed a glioma. In contrast, patients with an initially diffuse pattern of the lesion on MRI and increased ${ }^{18} \mathrm{~F}$ FET uptake had a clearly higher risk for developing a malignant glioma. ${ }^{13}$

Thus, combined assessment with ${ }^{18} \mathrm{~F}-\mathrm{FET}$ PET and MRI can identify subgroups of patients with a stable course in whom a watch-and-wait strategy is reasonable and patients with LGG who should receive early and aggressive treatment to avoid malignant transformation. 



Fig. 3. Studies obtained in a 44-year-old man. Upper: The MR images show a relatively circumscribed, nonenhancing right temporal lesion (arrowheads) without increased ${ }^{18} \mathrm{~F}$-FET uptake, as shown on the PET scan. Lower: The 6-month follow-up MR images demonstrate complete disappearance of the lesion.

\section{Monitoring of Neurooncological Treatment Using ${ }^{18} F-F E T$} PET

The evaluation of treatment response especially in patients with HGG is based on contrast enhancement and volumetric changes of lesion size seen on T2-weighted/ FLAIR MR images according to the recently defined Response Assessment in Neuro-Oncology Working Group criteria. ${ }^{68}$ Treatment monitoring of nonenhancing tumors like LGG, however, can be difficult using T2-weighted/ FLAIR MR images alone. Malignant tumor portions (for example, those that are WHO Grade III) may not exhibit contrast enhancement ${ }^{5}$ and, furthermore, T2-weighted/ FLAIR MRI-based signal hyperintensity represents a combination of infiltrating tumor cells, necrotic areas, tumor edema, and treatment-related leukoencephalopathy, such as that due to radiotherapy. ${ }^{1}$ Thus, in addition to morphological MRI there is a need for imaging tools that allow for a better assessment of therapeutic response and disease development.

Alternative targets for treatment monitoring are the change of treatment-related tumor metabolism. Therefore, imaging methods that measure metabolic processes in the tumor, such as the amino acid uptake in ${ }^{18} \mathrm{~F}$-FET PET, may assess and quantify therapeutic response more with more sensitivity than morphological imaging and may provide additional information to morphological MRI. Several studies, particularly in patients with HGG, have successfully evaluated the role of ${ }^{18} \mathrm{~F}$-FET PET in monitoring radiochemotherapy with temozolomide, chemotherapy, or experimental treatment modalities (for example, antiangiogenic treatment). ${ }^{14,15,26,43,44,47}$

In contrast to the management of $\mathrm{HGG}$, experience with ${ }^{18} \mathrm{~F}$-FET PET for monitoring of treatment in patients with LGG is limited. In a prospective study, ${ }^{18} \mathrm{~F}$-FET PET was compared with MRI in evaluating the response to


FIG. 4. Studies obtained in a 37-year-old man. Upper: The MR images show a small and nonenhancing left frontal lesion without increased ${ }^{18} \mathrm{~F}$-FET uptake on the PET scan. No biopsy was performed. Lower: The follow-up 4-year MR images reveal a completely unchanged lesion.

a dose-dense temozolomide regimen in 11 patients with progressive nonenhancing LGG WHO Grade II. ${ }^{70}$ According to the EORTC protocol 22033-26033, patients received $75 \mathrm{mg} / \mathrm{m}^{2}$ temozolomide per day over 21 days of every 28-day cycle. After initiation of treatment, the authors compared the reduction of the metabolically active tumor volume, as assessed by ${ }^{18} \mathrm{~F}$-FET PET, with the reduction of the tumor volume delineated by FLAIR images. In responding patients, a reduction of the metabolically active tumor volume after initiation of treatment could be observed earlier than volume reductions on FLAIR sequences. The mean time to maximal volume reduction was $8.0 \pm 4.4$ months for ${ }^{18} \mathrm{~F}-\mathrm{FET}$ and $15.0 \pm 3.0$ months for MRI.

The findings highlight the high diagnostic value of ${ }^{18}$ F-FET PET for detecting treatment response. Furthermore, the identification of nonresponders at an early stage of neurooncological treatment may help to minimize a negative impact on quality of life. However, further prospective treatment monitoring studies using ${ }^{18} \mathrm{~F}$-FET PET in patients with LGG are needed to confirm these observations.

\section{Conclusions and Future Aspects}

Diagnostic assessment of LGG using ${ }^{18} \mathrm{~F}-\mathrm{FET}$ PET permits a more specific representation of the spatial extent of the tumors than is possible using conventional MRI alone. This has been shown to be advantageous for the planning of biopsies, tumor resection, and other treatment options. Valuable prognostic information can be obtained at initial diagnosis to optimize an individual treatment strategy, and the treatment response can probably be judged early in the course of treatment.

Other advanced MRI methods such as MRS may 
also yield metabolic information that is markedly more specific than that obtainable by conventional MRI for the differentiation of tumor tissue from nonspecific changes. ${ }^{24} \mathrm{~A}$ relationship between increased ${ }^{18} \mathrm{~F}$-FET uptake and abnormal high choline concentration in gliomas as measured by MRS has been demonstrated. ${ }^{60}$ In contrast to PET, however, MRS can only be used to analyze selected small volumes or partial areas in single planes, and susceptibility artifacts often impair the quality of MRS scans. Furthermore, diffusion-weighted imaging has been considered, but its clinical relevance is not yet established ${ }^{71}$ Other modalities such as perfusion-weighted MRI are more readily available than PET and may yield information that is correlated with the degree of glioma malignancy. ${ }^{24}$ However, the diagnostic accuracy of this technique in comparison with ${ }^{18} \mathrm{~F}-\mathrm{FET}$ PET remains to be investigated.

Diffusion tensor imaging can contribute valuable diagnostic information on the involvement of white matter structures (for example, nerve pathways). Intial studies have demonstrated the potential benefit of integrating fiber tracking by diffusion tensor imaging and ${ }^{18} \mathrm{~F}-\mathrm{FET}$ PET ${ }^{58,59}$ These studies indicated complementary information and more detailed understanding of peritumoral fiber tract alterations in gliomas, which are more complex than previously thought.

The scientifically well-documented utility of ${ }^{18} \mathrm{~F}-$ FET PET of LGG seems to justify its introduction as a routine diagnostic technique for certain indications. The guidelines of the European and the German Association of Nuclear Medicine for brain tumor imaging using labeled amino acid analogs have been published in recent years. ${ }^{32,65}$ The logistical prerequisites for amino acid-based PET have become markedly less difficult to achieve in recent years since the introduction of ${ }^{18} \mathrm{~F}-\mathrm{FET}$ PET, and many centers in Europe have already integrated this approach into the routine diagnostic workup of patients with brain tumors.

Furthermore, the costs of ${ }^{18}$ F-FET PET imaging are relatively small in relation to the expenses of local or systemic treatment approaches and, consequently, the management of possible adverse effects. ${ }^{20,21}$

The future will also be strongly influenced by the integration of PET and MRI in one imaging device..$^{25}$ The advent of hybrid PET-MRI systems offers a multimodal approach for the investigation of brain tumors and improved patient comfort due to a significant reduction in measurement time and improved spatial and temporal coregistration of PET and MRI data.

\section{Disclosure}

The authors report no conflict of interest concerning the materials or methods used in this study or the findings specified in this paper.

Author contributions to the study and manuscript preparation include the following. Conception and design: Rapp, Galldiks. Drafting the article: Rapp. Critically revising the article: Floeth, Langen, Galldiks. Reviewed submitted version of manuscript: Floeth, Felsberg, Steiger, Sabel, Langen, Galldiks. Approved the final version of the manuscript on behalf of all authors: Rapp.

\section{References}

1. Ahluwalia MS, Wen PY: Antiangiogenic therapy for patients with glioblastoma: current challenges in imaging and future directions. Expert Rev Anticancer Ther 11:653-656, 2011

2. Barker FG II, Chang SM, Huhn SL, Davis RL, Gutin PH, McDermott MW, et al: Age and the risk of anaplasia in magnetic resonance-nonenhancing supratentorial cerebral tumors. Cancer 80:936-941, 1997

3. Baumert BG, Stupp R: Is there a place for radiotherapy in low-grade gliomas? Adv Tech Stand Neurosurg 35:159-182, 2010

4. Buckner JC, Gesme D Jr, O'Fallon JR, Hammack JE, Stafford $\mathrm{S}$, Brown PD, et al: Phase II trial of procarbazine, lomustine, and vincristine as initial therapy for patients with low-grade oligodendroglioma or oligoastrocytoma: efficacy and associations with chromosomal abnormalities. J Clin Oncol 21:251255, 2003

5. Chamberlain MC, Murovic JA, Levin VA: Absence of contrast enhancement on CT brain scans of patients with supratentorial malignant gliomas. Neurology 38:1371-1374, 1988

6. Crocetti E, Trama A, Stiller C, Caldarella A, Soffietti R, Jaal $\mathrm{J}$, et al: Epidemiology of glial and non-glial brain tumours in Europe. Eur J Cancer 48:1532-1542, 2012

7. Duffau H, Capelle L: Preferential brain locations of low-grade gliomas. Cancer 100:2622-2626, 2004

8. Ewelt C, Floeth FW, Felsberg J, Steiger HJ, Sabel M, Langen KJ, et al: Finding the anaplastic focus in diffuse gliomas: the value of Gd-DTPA enhanced MRI, FET-PET, and intraoperative, ALA-derived tissue fluorescence. Clin Neurol Neurosurg 113:541-547, 2011

9. Floeth FW, Pauleit D, Sabel M, Reifenberger G, Stoffels G, Stummer W, et al: 18F-FET PET differentiation of ring-enhancing brain lesions. J Nucl Med 47:776-782, 2006

10. Floeth FW, Pauleit D, Sabel M, Stoffels G, Reifenberger G, Riemenschneider MJ, et al: Prognostic value of O-(2-18Ffluoroethyl)-L-tyrosine PET and MRI in low-grade glioma. J Nucl Med 48:519-527, 2007

11. Floeth FW, Pauleit D, Wittsack HJ, Langen KJ, Reifenberger G, Hamacher K, et al: Multimodal metabolic imaging of cerebral gliomas: positron emission tomography with [18F] fluoroethyl-L-tyrosine and magnetic resonance spectroscopy. J Neurosurg 102:318-327, 2005

12. Floeth FW, Sabel M, Ewelt C, Stummer W, Felsberg J, Reifenberger G, et al: Comparison of (18)F-FET PET and 5-ALA fluorescence in cerebral gliomas. Eur J Nucl Med Mol Imaging 38:731-741, 2011

13. Floeth FW, Sabel M, Stoffels G, Pauleit D, Hamacher K, Steiger HJ, et al: Prognostic value of 18F-fluoroethyl-L-tyrosine PET and MRI in small nonspecific incidental brain lesions. J Nucl Med 49:730-737, 2008

14. Galldiks N, Langen KJ, Holy R, Pinkawa M, Stoffels G, Nolte $\mathrm{KW}$, et al: Assessment of treatment response in patients with glioblastoma using O-(2-18F-fluoroethyl)-L-tyrosine PET in comparison to MRI. J Nucl Med 53:1048-1057, 2012

15. Galldiks N, Rapp M, Stoffels G, Fink GR, Shah NJ, Coenen $\mathrm{HH}$, et al: Response assessment of bevacizumab in patients with recurrent malignant glioma using [(18)F]Fluoroethyl-Ltyrosine PET in comparison to MRI. Eur J Nucl Med Mol Imaging 40:22-33, 2013

16. Ginsberg LE, Fuller GN, Hashmi M, Leeds NE, Schomer DF: The significance of lack of MR contrast enhancement of supratentorial brain tumors in adults: histopathological evaluation of a series. Surg Neurol 49:436-440, 1998

17. Grier JT, Batchelor T: Low-grade gliomas in adults. Oncologist 11:681-693, 2006

18. Grosu AL, Astner ST, Riedel E, Nieder C, Wiedenmann N, Heinemann F, et al: An interindividual comparison of O-(2[18F]fluoroethyl)-L-tyrosine (FET)- and L-[methyl-11C]me- 
thionine (MET)-PET in patients with brain gliomas and metastases. Int J Radiat Oncol Biol Phys 81:1049-1058, 2011

19. Hamacher K, Coenen HH: Efficient routine production of the $18 \mathrm{~F}$-labelled amino acid O-2-18F fluoroethyl-L-tyrosine. Appl Radiat Isot 57:853-856, 2002

20. Heinzel A, Stock S, Langen KJ, Müller D: Cost-effectiveness analysis of amino acid PET-guided surgery for supratentorial high-grade gliomas. J Nucl Med 53:552-558, 2012

21. Heinzel A, Stock S, Langen KJ, Müller D: Cost-effectiveness analysis of FET PET-guided target selection for the diagnosis of gliomas. Eur J Nucl Med Mol Imaging 39:1089-1096, 2012

22. Heiss P, Mayer S, Herz M, Wester HJ, Schwaiger M, Senekowitsch-Schmidtke R: Investigation of transport mechanism and uptake kinetics of O-(2-[18F]fluoroethyl)-L-tyrosine in vitro and in vivo. J Nucl Med 40:1367-1373, 1999

23. Henson JW, Gaviani P, Gonzalez RG: MRI in treatment of adult gliomas. Lancet Oncol 6:167-175, 2005

24. Herholz K, Coope D, Jackson A: Metabolic and molecular imaging in neuro-oncology. Lancet Neurol 6:711-724, 2007

25. Herzog H, Langen KJ, Weirich C, Rota Kops E, Kaffanke J, Tellmann L, et al: High resolution BrainPET combined with simultaneous MRI. Nucl Med (Stuttg) 50:74-82, 2011

26. Hutterer M, Nowosielski M, Putzer D, Waitz D, Tinkhauser G, Kostron H, et al: O-(2-18F-fluoroethyl)-L-tyrosine PET predicts failure of antiangiogenic treatment in patients with recurrent high-grade glioma. J Nucl Med 52:856-864, 2011

27. Jansen NL, Graute V, Armbruster L, Suchorska B, Lutz J, Eigenbrod S, et al: MRI-suspected low-grade glioma: is there a need to perform dynamic FET PET? Eur J Nucl Med Mol Imaging 39:1021-1029, 2012

28. Keles GE, Lamborn KR, Berger MS: Low-grade hemispheric gliomas in adults: a critical review of extent of resection as a factor influencing outcome. J Neurosurg 95:735-745, 2001

29. Kiebert GM, Curran D, Aaronson NK, Bolla M, Menten J, Rutten EH, et al: Quality of life after radiation therapy of cerebral low-grade gliomas of the adult: results of a randomised phase III trial on dose response (EORTC trial 22844). Eur J Cancer 34:1902-1909, 1998

30. Kondziolka D, Lunsford LD, Martinez AJ: Unreliability of contemporary neurodiagnostic imaging in evaluating suspected adult supratentorial (low-grade) astrocytoma. J Neurosurg 79:533-536, 1993

31. Kunz M, Thon N, Eigenbrod S, Hartmann C, Egensperger R, Herms J, et al: Hot spots in dynamic (18)FET-PET delineate malignant tumor parts within suspected WHO grade II gliomas. Neuro Oncol 13:307-316, 2011

32. Langen KJ, Bartenstein P, Boecker H, Brust P, Coenen HH, Drzezga A, et al: [German guidelines for brain tumour imaging by PET and SPECT using labelled amino acids.] Nucl Med (Stuttg) 50:167-173, 2011 (Ger)

33. Langen KJ, Hamacher K, Weckesser M, Floeth F, Stoffels G, Bauer D, et al: O-(2-[18F]fluoroethyl)-L-tyrosine: uptake mechanisms and clinical applications. Nucl Med Biol 33:287-294, 2006

34. Langen KJ, Jarosch M, Mühlensiepen H, Hamacher K, Bröer $\mathrm{S}$, Jansen P, et al: Comparison of fluorotyrosines and methionine uptake in F98 rat gliomas. Nucl Med Biol 30:501-508, 2003

35. Langen KJ, Tatsch K, Grosu AL, Jacobs AH, Weckesser M, Sabri O: Diagnostics of cerebral gliomas with radiolabeled amino acids. Dtsch Arztebl Int 105:55-61, 2008

36. Louis DN, Ohgaki H, Wiestler OD, Cavenee WK, Burger PC, Jouvet A, et al: The 2007 WHO classification of tumours of the central nervous system. Acta Neuropathol 114:97-109, 2007

37. Möller-Hartmann W, Herminghaus S, Krings T, Marquardt G, Lanfermann H, Pilatus U, et al: Clinical application of proton magnetic resonance spectroscopy in the diagnosis of intracranial mass lesions. Neuroradiology 44:371-381, 2002
38. Muragaki Y, Chernov M, Maruyama T, Ochiai T, Taira T, Kubo O, et al: Low-grade glioma on stereotactic biopsy: how often is the diagnosis accurate? Minim Invasive Neurosurg 51:275-279, 2008

39. Pauleit D, Floeth F, Hamacher K, Riemenschneider MJ, Reifenberger G, Müller HW, et al: O-(2-[18F]fluoroethyl)-L-tyrosine PET combined with MRI improves the diagnostic assessment of cerebral gliomas. Brain 128:678-687, 2005

40. Pauleit D, Stoffels G, Bachofner A, Floeth FW, Sabel M, Herzog H, et al: Comparison of (18)F-FET and (18)F-FDG PET in brain tumors. Nucl Med Biol 36:779-787, 2009

41. Pichler R, Dunzinger A, Wurm G, Pichler J, Weis S, Nussbaumer K, et al: Is there a place for FET PET in the initial evaluation of brain lesions with unknown significance? Eur J Nucl Med Mol Imaging 37:1521-1528, 2010

42. Pignatti F, van den Bent M, Curran D, Debruyne C, Sylvester $\mathrm{R}$, Therasse $\mathrm{P}$, et al: Prognostic factors for survival in adult patients with cerebral low-grade glioma. J Clin Oncol 20:2076-2084, 2002

43. Piroth MD, Holy R, Pinkawa M, Stoffels G, Kaiser HJ, Galldiks N, et al: Prognostic impact of postoperative, pre-irradiation (18)F-fluoroethyl-1-tyrosine uptake in glioblastoma patients treated with radiochemotherapy. Radiother Oncol 99: 218-224, 2011

44. Piroth MD, Pinkawa M, Holy R, Klotz J, Nussen S, Stoffels $\mathrm{G}$, et al: Prognostic value of early [18F]fluoroethyltyrosine positron emission tomography after radiochemotherapy in glioblastoma multiforme. Int J Radiat Oncol Biol Phys 80:176-184, 2011

45. Pirotte B, Goldman S, Dewitte O, Massager N, Wikler D, Lefranc $\mathrm{F}$, et al: Integrated positron emission tomography and magnetic resonance imaging-guided resection of brain tumors: a report of 103 consecutive procedures. J Neurosurg 104:238253, 2006

46. Pirotte BJ, Levivier M, Goldman S, Massager N, Wikler D, Dewitte O, et al: Positron emission tomography-guided volumetric resection of supratentorial high-grade gliomas: a survival analysis in 66 consecutive patients. Neurosurgery 64: 471-481, 2009

47. Pöpperl G, Goldbrunner R, Gildehaus FJ, Kreth FW, Tanner P, Holtmannspötter M, et al: O-(2-[18F]fluoroethyl)-L-tyrosine PET for monitoring the effects of convection-enhanced delivery of paclitaxel in patients with recurrent glioblastoma. Eur J Nucl Med Mol Imaging 32:1018-1025, 2005

48. Pouratian N, Schiff D: Management of low-grade glioma. Curr Neurol Neurosci Rep 10:224-231, 2010

49. Rapp M, Heinzel A, Galldiks N, Stoffels G, Felsberg J, Ewelt C, et al: Diagnostic performance of 18F-FET PET in newly diagnosed cerebral lesions suggestive of glioma. J Nucl Med [epub ahead of print], 2012

50. Reifenberger G, Louis DN: Oligodendroglioma: toward molecular definitions in diagnostic neuro-oncology. J Neuropathol Exp Neurol 62:111-126, 2003

51. Salber D, Stoffels G, Oros-Peusquens AM, Shah NJ, Reifenberger G, Hamacher K, et al: Comparison of O-(2-18Ffluoroethyl)-L-tyrosine and L-3H-methionine uptake in cerebral hematomas. J Nucl Med 51:790-797, 2010

52. Salber D, Stoffels G, Pauleit D, Oros-Peusquens AM, Shah NJ, Klauth P, et al: Differential uptake of O-(2-18F-fluoroethyl)L-tyrosine, L-3H-methionine, and 3H-deoxyglucose in brain abscesses. J Nucl Med 48:2056-2062, 2007

53. Salber D, Stoffels G, Pauleit D, Reifenberger G, Sabel M, Shah NJ, et al: Differential uptake of [18F]FET and [3H]l-methionine in focal cortical ischemia. Nucl Med Biol 33:1029-1035, 2006

54. Shaw E, Arusell R, Scheithauer B, O’Fallon J, O’Neill B, Dinapoli $\mathrm{R}$, et al: Prospective randomized trial of low- versus high-dose radiation therapy in adults with supratentorial lowgrade glioma: initial report of a North Central Cancer Treat- 
ment Group/Radiation Therapy Oncology Group/Eastern Cooperative Oncology Group study. J Clin Oncol 20:22672276, 2002

55. Shaw EG, Berkey B, Coons SW, Bullard D, Brachman D, Buckner JC, et al: Recurrence following neurosurgeon-determined gross-total resection of adult supratentorial low-grade glioma: results of a prospective clinical trial. Clinical article. J Neurosurg 109:835-841, 2008

56. Smith JS, Chang EF, Lamborn KR, Chang SM, Prados MD, Cha S, et al: Role of extent of resection in the long-term outcome of low-grade hemispheric gliomas. J Clin Oncol 26:1338-1345, 2008

57. Soffietti R, Baumert BG, Bello L, von Deimling A, Duffau $\mathrm{H}$, Frénay M, et al: Guidelines on management of low-grade gliomas: report of an EFNS-EANO Task Force. Eur J Neurol 17:1124-1133, 2010

58. Stadlbauer A, Hammen T, Grummich P, Buchfelder M, Kuwert T, Dörfler A, et al: Classification of peritumoral fiber tract alterations in gliomas using metabolic and structural neuroimaging. J Nucl Med 52:1227-1234, 2011

59. Stadlbauer A, Pölking E, Prante O, Nimsky C, Buchfelder M, Kuwert T, et al: Detection of tumour invasion into the pyramidal tract in glioma patients with sensorimotor deficits by correlation of (18)F-fluoroethyl-L-tyrosine PET and magnetic resonance diffusion tensor imaging. Acta Neurochir (Wien) 151:1061-1069, 2009

60. Stadlbauer A, Prante O, Nimsky C, Salomonowitz E, Buchfelder M, Kuwert T, et al: Metabolic imaging of cerebral gliomas: spatial correlation of changes in O-(2-18F-fluoroethyl)L-tyrosine PET and proton magnetic resonance spectroscopic imaging. J Nucl Med 49:721-729, 2008

61. Stiver SI: Angiogenesis and its role in the behavior of astrocytic brain tumors. Front Biosci 9:3105-3123, 2004

62. Stockhammer F, Plotkin M, Amthauer H, van Landeghem FK, Woiciechowsky C: Correlation of F-18-fluoro-ethyl-tyrosin uptake with vascular and cell density in non-contrast-enhancing gliomas. J Neurooncol 88:205-210, 2008

63. Stummer W, Pichlmeier U, Meinel T, Wiestler OD, Zanella F, Reulen HJ: Fluorescence-guided surgery with 5-aminolevulinic acid for resection of malignant glioma: a randomised controlled multicentre phase III trial. Lancet Oncol 7:392401,2006
64. van den Bent MJ, Afra D, de Witte O, Ben Hassel M, Schraub S, Hoang-Xuan K, et al: Long-term efficacy of early versus delayed radiotherapy for low-grade astrocytoma and oligodendroglioma in adults: the EORTC 22845 randomised trial. Lancet 366:985-990, 2005

65. Vander Borght T, Asenbaum S, Bartenstein P, Halldin C, Kapucu O, Van Laere K, et al: EANM procedure guidelines for brain tumour imaging using labelled amino acid analogues. Eur J Nucl Med Mol Imaging 33:1374-1380, 2006

66. Weber WA, Wester HJ, Grosu AL, Herz M, Dzewas B, Feldmann HJ, et al: O-(2-[18F]fluoroethyl)-L-tyrosine and L[methyl-11C]methionine uptake in brain tumours: initial results of a comparative study. Eur J Nucl Med 27:542-549, 2000

67. Weckesser M, Langen KJ, Rickert CH, Kloska S, Straeter R, Hamacher K, et al: O-(2-[18F]fluorethyl)-L-tyrosine PET in the clinical evaluation of primary brain tumours. Eur J Nucl Med Mol Imaging 32:422-429, 2005

68. Wen PY, Macdonald DR, Reardon DA, Cloughesy TF, Sorensen AG, Galanis E, et al: Updated response assessment criteria for high-grade gliomas: response assessment in neurooncology working group. J Clin Oncol 28:1963-1972, 2010

69. Wester HJ, Herz M, Weber W, Heiss P, SenekowitschSchmidtke R, Schwaiger M, et al: Synthesis and radiopharmacology of O-(2-[18F]fluoroethyl)-L-tyrosine for tumor imaging. J Nucl Med 40:205-212, 1999

70. Wyss M, Hofer S, Bruehlmeier M, Hefti M, Uhlmann C, Bärtschi E, et al: Early metabolic responses in temozolomide treated low-grade glioma patients. J Neurooncol 95:87-93, 2009

71. Yang I, Aghi MK: New advances that enable identification of glioblastoma recurrence. Nat Rev Clin Oncol 6:648-657, 2009

Manuscript submitted October 11, 2012.

Accepted December 10, 2012.

Please include this information when citing this paper: DOI: 10.3171/2012.12.FOCUS12336.

Address correspondence to: Marion Rapp, M.D., Department of Neurosurgery, University of Duesseldorf, Moorenstrasse 5, 40225 Duesseldorf, Germany.email: marion.rapp@uni-duesseldorf.de. 